\title{
BLOCKCHAIN FOR INDIAN AGRICULTURE: A REVOLUTION
}

\author{
Mehtab Alam, Dr. Ihtiram Raza Khan* \\ Jamia Hamdard, New Delhi \\ *Corresponding author. E-mail: erkhan2007@gmail.com
}

\begin{abstract}
The most challenging problem before the world is providing enough food for the gigantic leap in population. There are numerous reasons for the shortage of food and technological innovations in agriculture are required to overcome the shortages in food supply. Sustainable Development goals (SDGs) provides the futuristic vision and ICT along with other latest technologies will help achieve these development goals at a brisk speed. Recent technological developments as use of mobilebroadband access devices, Internet of Things (IoT), Specialized Robots, Drones, big data analytics and Artificial Intelligence has given farmers tools and technologies to scale agricultural production and marketing of their agricultural products.
\end{abstract}

In this paper, we will discuss how Smart Agriculture is changing the face of agriculture in Budaun, a small city in Uttar Pradesh. Smart agriculture coupled with block chain technology is being used to achieve sustainability in agriculture growth. The production/yield has risen by over $20 \%$ and the profits have increased by over $30 \%$ with the new technology.

Keywords: Block chain, Smart agriculture, Sustainable development, distributed ledger, Artificial Intelligence(AI), Information and communication technology(ICT)

\section{INTRODUCTION}

Agriculture is the biggest source of income of farmers. Data projects $75 \%$ of rural population dependent on agriculture. India has been doing exceptionally well in agriculture domain after achieving Harit Kranti/Green revolution. India is in the list of top 15 exporters of agricultural products. In India, agriculture is the main sector for food security, nutritional security and sustainable development \& for poverty alleviation.

Just as we were looking for ways of increasing profits, Technology and Innovation (AI, IoT, Big data and analytics) has completely changed the scenario. Block chain technology is helping us with accurate data about Inventory, farming, credit scores and food tracking.

With its launch in 2009, crypto currencies have gained attention from all kinds of industries as well as academia. Bit coin, the first crypto currency, currently has a market capitalization of 117.81 billion USD [1]. Bit coin functions and operates using block chain technology. Block chain is a list of records that keeps increasing or growing as new information, called blocks, are added to it. These blocks are linked using cryptography [2]. Every block consists of cryptographic hash value of the block previous to it, a unique time stamp, transactional data, and a calculated hash of its own complete block. Block chain has the potential to impact the way agricultural business is done and will result in increased productivity and better decisions.

In this research paper we will discuss latest IOT and AI technology and how it could transform the agriculture sector in India. Sustainable smart agriculture is the reality of the future.

\section{PROBLEM STATEMENT}

Rural areas face a number of issues in day to day agriculture operations. The agriculture community in Uttar Pradesh is occupied with other difficulties as well.

The questions asked are

- What are the agricultural needs of the farmers' community in India and especially my small hometown Budaun that will lead to upliftment of living standards?

- What technology is being used and what more can be added to make the total profit higher and agriculture sustainable.

III THE STATE OF AGRICULTURE IN DISTRICT BUDAUN (U.P.) 
We are talking of a small district in middle Uttar Pradesh. District Budaun is in Western Plain Zone of U.P. The temperature ranges from 4.5 degree $C$ to 45.4 degree C. The soil of city isalluvial. Rainfall is during June and October with annual rainfall is $882 \mathrm{~mm}$.

Agriculture crops are wheat, mustard, potato, paddy, sugarcane, maize, bajra, toria while Horticulture crops are guava, mango, papaya, capsicum, brinjal, chilli, tomato, muskmellon and watermellon.

The main crops in the selected city Budaun are Wheat, Rice and Sugarcane. Wheat's yield in 1 Bighe land is approximately 4 Quintals at a rough cost of Rs. 1800/per quintal.

Rice's yield is Basmati where 1 Bigha produces 3 Quintals of Rice at the cost of Rs.3000/- per quintal.

Sugarcane is a rich crop where 1 Bigha produces 50/60 quintals of Sugarcane at the cost of Rs. 325/- per Quintal.

Small cities have their own problems. Farmers have low yield and don't usually get the profits they deserve. Transport, roads, irrigation facilities, supply chain and many other factors are hindrances in the overall functioning.

With AI and IoT, things are changing and the yield is increasing and Block chain when combined with Smart Agriculture, things are dramatically changing.

\section{POTENTIAL OF IOT, AI AND BLOCKCHAIN IN AGRICULTURE}

Most of the failures in agriculture business are related to the unavailability of correct data. Internet of Things (IOT) offers a great promise in various agricultural business functional areas in terms of efficiency enhancement, correctness of information, profit gains and even the development of new business processes and models. AI in addition to IOT is giving businesses a new horizon to chase.
A block chain is a distributed data set of records, also known as a public ledger, consisting of all the transactions that have taken place and are shared over the network [3]. Each transaction taking place is verified by all the participant computer systems present on the network. Once the data has been entered and verified, it can never be erased or even edited. To better understand it using a basic analogue, it is easier to steal a chocolate from a chocolate stand kept in isolated place, than stealing a chocolate from a chocolate stand kept in a market place, being observed by a lot of people. Block chain is a chain of interconnected blocks of data. Block consists of the data and the chain resembles the link/topology of the data [4].

Although Bitcoin is the most known use of block chain technology, block chain can be applied to various other applications. It does not require any central entity for verification; therefore, it can be used for various financial services such as digital assets, remittance and various online payments [5]. Block chain is also coming out to be a promising technology for the next generation of internet interaction systems. Like, smart contracts [6], public services [7], Internet of things (IoT) [8], reputation system [9], security services [10] etc.

A block chain is a chain of blocks, which stores all the details of the transaction like a legacy public ledger [11].To better understand the working of block chain we will first compare it with the traditional system. The main difference between the two entity is centralization. In traditional system all the records are stored on a centralized database [14], while in block chain system, each member has a copy of all the records and the changes made and each member can view the origin of the data [15]. If a malicious user tries to change some information in the traditional system it will be very hard and time consuming to detect and rectify. But in case of block chain, if some inconsistency occurs, the technology immediately identifies and corrects the unreliable information since every user has the correct information

with them 


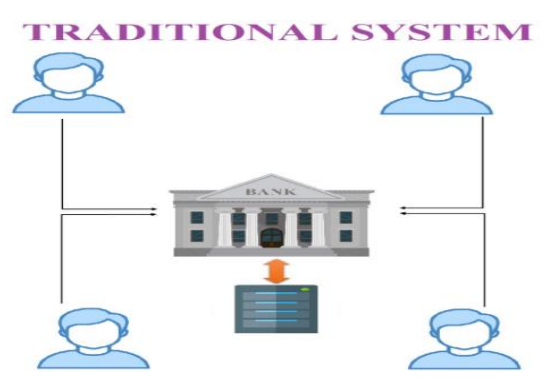

V

\section{BENEFITS OF IOT, AI AND BLOCKCHAIN IN ARGICULTURE}

This collaboration of block chain into agriculture aims to provide mobile-based services which would assist farmers in analysing and monitoring the information provided by the block chain network such as financial transactions, farm inputs, demand of crops in market, market rate, supply chain, land holding etc. Thus, this would ensure the transparency and would help farmers to take effective decision.

\section{- $\quad$ Trace-ability}

Small-scale farmers often do not get the right price for their produce. Block chain enables farmers and customers to trace agricultural produce and skip dealing with intermediaries. In addition, block chain technology would give a clear picture of trending prices and would eventually help in increasing the income of farmers. ICRISAT considers this collaboration as the first step and further aims to employ Block chain technology in creating an E-agricultural system.

\section{- $\quad$ Registration of Land}

Andhra Pradesh government has collaborated with Chroma Way (a Swedish company) for development of a block chain-based platform through which record keeping of land registration can be conducted. This will enable farmers to directly contact with the government thereby, saving them from frauds. Other Indian states will follow on Andhra Pradesh footsteps if this pilot project is successful.

\section{- Food Security}

Block chain would help in tracing food, this would let the farmers and customers keep track of the transactions occurring at every level. Block chain to detect any fraud from farm till it reaches the final consumer.

- Verified Agri-inputs and Monitored Subsidy Disbursal

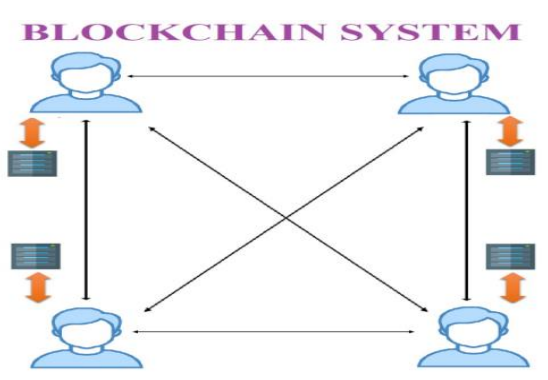

Block chain technology will help farmers buy verified inputs by monitoring the transactions of the product from the very beginning till it reaches them. The funds or subsidiary provided by the government almost reduced by significant percentage before reaching the farmers. Block chain provides a decentralized and transparent platform which would help the government and farmers to trace the transactions at each level.

Thus, Block chain seems to be a promising technology which could provide solutions to the problems faced by the Indian agricultural sector.

\section{DATA AND RESULTS}

Following is the data of Wheat and Rice production for years 1997-2019 in five years duration for the district that we have chosen for Smart Agriculture and undergoing technological innovations. The data refers to district wise, crop wise, season wise and year wise data on crop covered area (Hectare) and production (Tonnes).https://data.gov.in/catalog/district-wiseseason-wise-crop-production-statistics

Table 1: Wheat production in Budaun

\begin{tabular}{|c|c|c|}
\hline Year & $\begin{array}{c}\text { Wheat } \\
\text { production(Tonnes) }\end{array}$ & \% Growth \\
\hline 1997 & 721587 & \\
\hline 2002 & 772859 & 6.634069 \\
\hline 2007 & 837259 & 7.691766 \\
\hline 2012 & 765401 & -9.38828 \\
\hline 2017 & 638009 & -19.9671 \\
\hline $\mathbf{2 0 1 9}$ & $\mathbf{9 2 7 4 6 5}$ & 31.20937 \\
\hline & & \\
\hline
\end{tabular}


The highest \% growth in 2018-19 was 31\% which points to the technological advances and the benefits of new technology.

Table 2: Rice production in Budaun

\begin{tabular}{|c|c|c|}
\hline & Rice & \\
Year & production(Tonnes) & \\
& & \% Growth \\
\hline 1997 & 141053 & \\
\hline
\end{tabular}

\begin{tabular}{|l|c|r|}
2002 & 76092 & -85.3717 \\
\hline 2007 & 163724 & 53.52422 \\
\hline 2012 & 191329 & 14.42803 \\
\hline 2017 & 166790 & -14.7125 \\
\hline $\mathbf{2 0 1 9}$ & $\mathbf{1 9 9 3 4 5}$ & 16.33098 \\
\hline
\end{tabular}

The $\%$ growth in $2018-19$ was $16 \%$ which points to the technological advances and the benefits of new technology after seeing a decline of $-14 \%$ in 2017.

Figure: Wheat and rice yield comparison
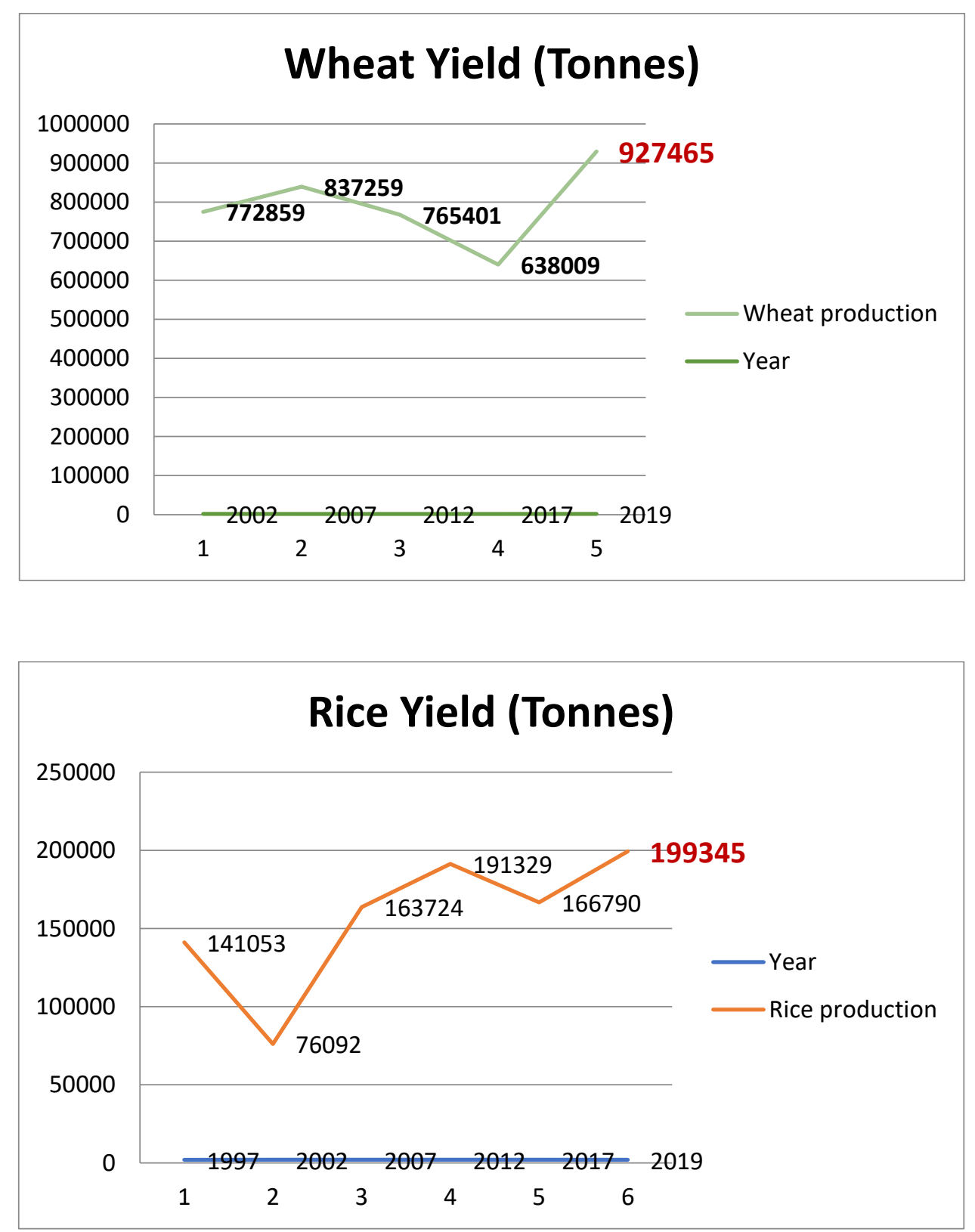

Google Colab, Python and official Budaun website (https://data.gov.in/catalog/district-wise-season-wisecrop-production-statistics) were used to simulate the res 
ults.

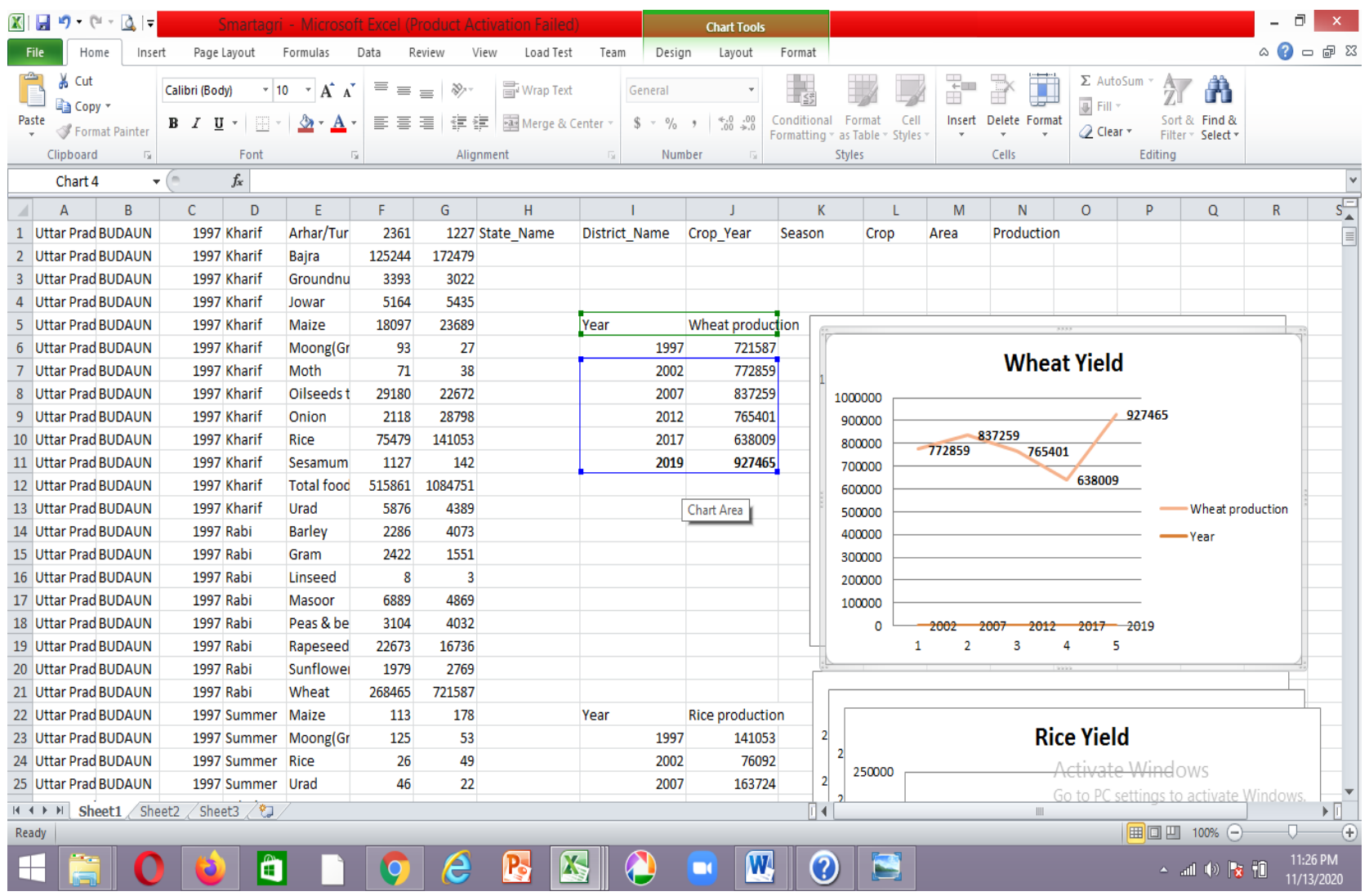

\section{VII}

\section{CONCLUSION}

Technology can cater most challenges our farmers face. It can assist them with predicting climate accurately, decrease the use of water and increase the yield and raising their net profit margins. Block chain is a growing technology. Even though it has begun to revolutionize many industries, there is still a long way to go. However, it's becoming increasingly clear that there are limitless opportunities for block chain technology in the agriculture industry.

The use of Mobile broadband access devices, IoT, Robots, Drones, Data Analytics and Artificial Intelligence have helped Indian farmers tools and technologies to improve production and marketing of their products. The coming up of Block chain added to the recent innovations have increased the crop output/yield since 2019 onwards. Farmers are able to yield more wheat, rice, sugarcane and other crops by the use of AI, IoT and Block chain. Our throughput has clearly increased by over $31 \%$ and $16 \%$ for wheat and rice respectively and we are targeting more.
We are getting a better price of wheat, rice and sugarcane by using the supply chain of block chain technology. Our profits for these three crops have gone up by $30 \%$ and intend to use the block chain for other crops too. Other farmers are taking up the technology and now we can look for a better future by getting a better price for a better yield.

\section{REFERENCES}

[1] J. Rudden, " Market capitalization of Bitcoin from 4th quarter 2013 to 1st quarter 2020," 03 August 2020. [Online].

Available: https://www.statista.com/statistics/377382/bitcoinmarket-capitalization/.

[2] M. Alam, I. R. Khan and S. Tanwer, "Blockchain Technology: A Critical Review and Its Proposed Use in E-Voting in India," SSRN Electronic Journal, 2020.

[3] M. Crosby, P. Pattanayak, S. Verma and V. Kalyanaraman, "Blockchain technology: Beyond bitcoin," Applied Innovation 2, pp. 6-10, 2016.

[4] D. Yaga, P. Mell, N. Roby and K. Scarfone, "Blockchain Technology Overview," Draft NISTIR 8202 NIST, 2018. 
[5] G. W. Peters and E. Panayi, "Understanding modern banking ledgers through blockchain technologies: Future of transaction processing and smart contracts on the internet of money," Social Science Research Network, 2015.

[6] A. Kosba, A. Miller, E. Shi, Z. Wen and C. Papamanthou, "Hawk: the blockchain model of cryptography and privacy-preserving smart contracts," in IEEE Symposium on Security and Privacy (SP), San Jose, CA, USA, 2016.

[7] B. W. Akins, J. L. Chapman and J. M. Gordon, "A Whole New World:Income Tax Considerations of the Bitcoin Economy," 2013. [Online]. Available: https://www.antshares.org.

[8] M. Alam, I. R. Khan and S. Tanweer, "IoT in Smart Cities: A survey," Juni Khyat, pp. 89-101, 2020.

[9] M. Sharples and J. Domingue, "The blockchain and kudos: A distributed system for educational record, reputation and reward," in 11th European Conference on Technology Enhanced Learning (EC-TEL 2015), Lyon, France, 2015.

[10] C. Noyes, "Bitav: Fast Anti-Malware by Distributed Blockchain Consensus and Feedforward Scanning," 2016.

[11] D. Lee Kuo Chuen, Handbook of Digital Currency, Elsevier, 2015.

[12] R. Zhang, R. Xue and L. Liu, "Security and Privacy on Blockchain," ACM Computing Surveys, vol. 52, no. 3, pp. 1-34, 2019.

[13] S. Omohundro, "Survey on Blockchain Technologies and Related Services," in Cryptocurrencies, smart contracts, and artificial intelligence', AI Matters, 2015.

[14] A. Mohammad and B. M. Saleh, "Centralized Database: A Prerequisite for Security and Sustainable Development in Nigeria," International Journal of Innovative Research in Computer Science \& Technology, vol. 5, no. 1, pp. 209-213, 2017.

[15] M. Nofer, P. Gomber, O. Hinz and D. Schiereck, "Blockchain," Business \& Information Systems Engineering, vol. 59, no. 3, pp. 183-187, 2017. 